\title{
Response to different benznidazole doses in animal models of chronic phase Chagas disease: a critical review
}

\author{
Cauê Benito Scarim ${ }^{[1]}$, Aline Rimoldi Ribeiro ${ }^{[2]}$, João Aristeu da Rosa ${ }^{[3]}$ \\ and Chung Man Chin ${ }^{[1]}$
}

\author{
[1]. Departamento de Fármacos e Medicamentos, Faculdade de Ciências Farmacêuticas, \\ Universidade Estadual Paulista Júlio de Mesquita Filho, Araraquara, SP, Brasil. \\ [2]. Departamento de Parasitologia, Instituto de Biologia, Universidade Estadual de Campinas, Campinas, SP, Brasil. \\ [3]. Departamento de Ciências Biológicas, Faculdade de Ciências Farmacêuticas, \\ Universidade Estadual Paulista Júlio de Mesquita Filho, Araraquara, SP, Brasil.
}

\begin{abstract}
Chagas disease is a protozoan infection that was identified over a century ago. No drugs are available to treat the indeterminate and determinate chronic phases of the disease. Success of a drug design is dependent on correct biological evaluation. Concerning new drug designs for Chagas disease, it is essential to first identify the most effective, existing, experimental chronic protocols that can be used for comparison purposes. Here, we present a literature review regarding experimental models with chronic Chagas disease to evaluate the efficacy of benznidazole (BZN). We searched literature published in PubMed and Web of Science databases, using these keywords: animal model, BZN, Chagas disease, T. cruzi, and chronic phase, with no timeframe limitations. We excluded articles involving acute phase animal models and/or those without BZN treatment. The selected studies were conducted using different BZN concentrations (10mg-100mg) involving several different periods (5-70 days). Concentrations and durations of use are directly related to side effects, but do not prevent chronic tissue lesions. BZN use during the late/ chronic phases of Chagas disease is unable to eliminate amastigote forms present in infected tissues. This study suggests the administration of a lower BZN concentration $(<100 \mathrm{mg} / \mathrm{kg} / \mathrm{day})$ during the chronic phase of the animal model, as this had been reported to result in fewer side effects.
\end{abstract}

Keywords: Benznidazole. Chagas disease. Chronic phase.

\section{INTRODUCTION}

Chagas disease is an endemic zoonosis that affects 8 million people worldwide, originating in Latin America, and endemic in 21 Latin American countries ${ }^{1}$. The reach of the parasite is expanding due to globalization and the increasing number of infections occurring in developed countries, such as the USA, Spain, and Japan. More than 100 years after it was first described, there remain only two available drugs for treatment, namely, benznidazole (BZN) and nifurtimox. These drugs have been in use for more than four decades, and the discovery of new drugs is urgently needed. However, in some countries, such as Brazil, BZN is the only available drug, which is highly active in the acute phase of the disease but its efficacy in the chronic phase of Chagas disease remains controversial. Moreover, there is little evidence to support BZN as totally effective in parasite elimination ${ }^{2-4}$, and some

Corresponding author: Cauê Benito Scarim.

e-mail: cauebenitos@gmail.com

Received 28 September 2017

Accepted 18 April 2018 studies have observed efficiency only in the indeterminate form of the chronic phase in children ${ }^{5-7}$. These drugs have also shown questionable efficacy in the chronic phase and several adverse reactions have been reported, mainly in adults, such as anorexia, weight loss, nausea, vomiting, insomnia, depression, convulsions, dizziness, headache, drowsiness, muscle pain, loss of balance, mental confusion, memory problems, peripheral neuropathies, mucosal edema, liver intolerance, and cutaneous manifestations ${ }^{8-11}$. Since discovering the disease, no drug has shown efficacy for the indeterminate and chronic phases of the disease $\mathrm{e}^{12-17}$. One step towards achieving success in new drug development involves adequate animal in vivo testing. Development of a mouse model with chronic Chagas disease is difficult and depends on the choice of the animal, the strain of Trypanosoma cruzi (T. cruzi) the amount of inoculated parasite load, confirmation of the disease stage, time/dose of the drug in tests, and maintenance of animal survival at the end of the experiment. The current study presents the experimental animal models that have been used and highlights the effect of BZN in the indeterminate and determinate chronic infection phases.

The most recent in vivo model that can identify the parasite during the experimental procedure is based on modified 
parasites that are highly sensitive to in vivo imaging, using a bioluminescence imaging system based on T. cruzi $^{18-20}$. However, this methodology is not extensively used in every laboratory. Table 1, Table 2 and Table 3 indicate the studies that have reported the effect of BZN in indeterminate/chronic infections and the experiments for chronic infections in several T. cruzi strains (Table $\mathbf{1}^{17-19,22}$, Table $\mathbf{2}^{17,18,21-23}$, Table $3^{18,24-29}$ ).

Immunosuppression alters the natural development of the disease, predetermining the development or reactivation of opportunistic infections. This is especially true for Chagas disease $\mathrm{e}^{30,31}$, particularly in animal models, where immunosuppression is simply applied to evaluate a sterile cure. This effect occurs despite efforts to produce a perfect chronic phase model that involves the use of BZN.

A current strategy in use involves therapeutic doses of BZN as part of a combination therapy for Chagas disease. This entails therapeutic regimens with low concentrations to decrease toxicity and consequently reduce side effects due to typical BZN therapy. One study ${ }^{32}$ has evaluated the effect of an antihypertensive medication in association with a standard anti-T. cruzi drug. That study used enalapril $(25 \mathrm{mg} / \mathrm{kg})$ and BZN $(100 \mathrm{mg} / \mathrm{kg})$ separately and together for 30 days in animal models infected with the VL-10 strain of T. cruzi, mainly to evaluate chronic cardiac inflammatory parameters, levels of chemokines (CCL2, CCL5), IL-10, creatine kinases (CKs), and C-reactive protein serum 120 days post-infection. The authors reported that the combination of enalapril and BZN could decrease the biomarker levels of CK, CK-MB, and C-reactive proteins during the chronic phase of the disease, and also reduce the intensity of inflammatory infiltrates in the heart. Two years later, the same authors ${ }^{33}$ evaluated this same therapeutic combination (enalapril/ BZN) during the chronic phase of the disease in an animal model infected with the VL-10 strain of T. cruzi. However, in their latter study they used several different concentrations: BZN $(100,80$, and $60 \mathrm{mg} / \mathrm{kg})$, enalapril $(25,20$, and $15 \mathrm{mg} / \mathrm{kg})$, and both $(100+25 ; 80+20 ; 60+15 \mathrm{mg} / \mathrm{kg}$, respectively). These concentrations were administered for 20 days orally by gavage, and euthanization occurred 120 days post-infection. This was performed to decrease toxicity and cardiac lesions, as well as to produce the same anti-T. cruzi effect. Their data demonstrated that a therapeutic combination resulted in an approximate $20 \%$ decrease in the parameter concerning inflammatory infiltrates when compared to standard BZN therapy. However, the therapeutic combination $(100+25$ and $80+20 \mathrm{mg} / \mathrm{kg})$ enhanced IL-10 levels, and also decreased cardiac inflammatory infiltrates evaluated in the histopathological analysis.

TABLE 1: Experimental studies involving chronic phase Chagas disease in animal models with immunosuppression: $B Z \mathrm{~N}=100 \mathrm{mg} / \mathrm{kg} / \mathrm{day}$.

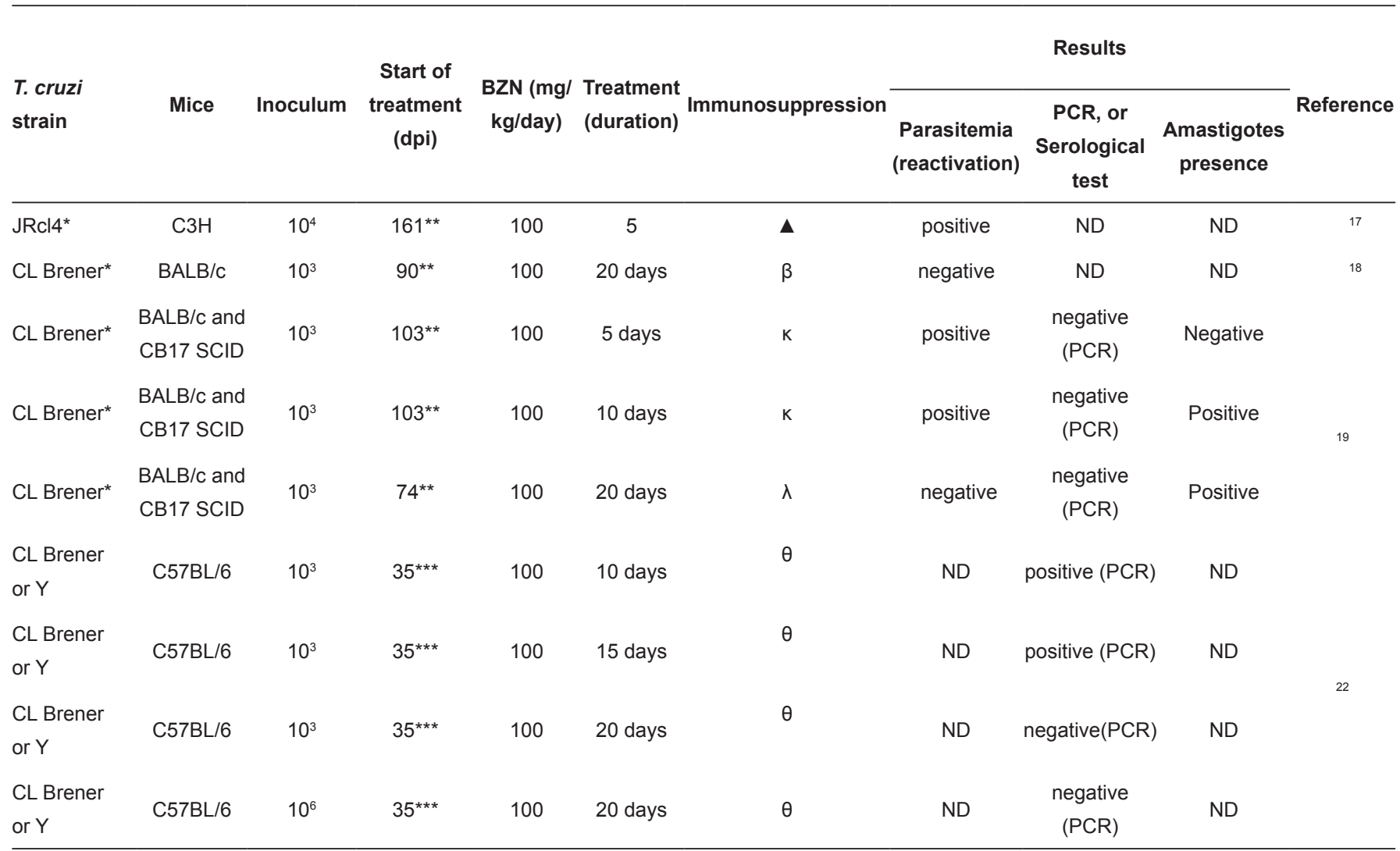

BZN: benznidazole; T. cruzi: Trypanosoma cruzi; dpi: days post-infection; PCR: polymerase chain reaction; ND: not determined; $\mathbf{\Lambda}$ : cyclophosphamide (200mg/ $\mathrm{kg}$ ) on days 175,179 , and $183 \mathrm{dpi}$; bid: bis in die (twice daily); $\boldsymbol{\beta}$ : cyclophosphamide (200mg/kg) on days 124, 127, 130, and $133 \mathrm{dpi}$; $\mathbf{k}$ : cyclophosphamide $(200 \mathrm{mg} / \mathrm{kg})$ on days 124,128 , and $132 \mathrm{dpi} ; \boldsymbol{\lambda}$ : cyclophosphamide $(200 \mathrm{mg} / \mathrm{kg})$ on days 113,118 , and $128 \mathrm{dpi} ; \boldsymbol{\theta}$ : cyclophosphamide $(200 \mathrm{mg} / \mathrm{kg})$ four cycles of cyclophosphamide with each cycle lasting one week. *Bioluminescent bloodstream-form of $T$. cruzi. ${ }^{* *}$ Chronic phase; ${ }^{* *}$ Late acute phase. 
TABLE 2: Experimental studies involving chronic phase Chagas disease in animal models with immunosuppression: BZN $\leq 50 \mathrm{mg} / \mathrm{kg} / \mathrm{day}$.

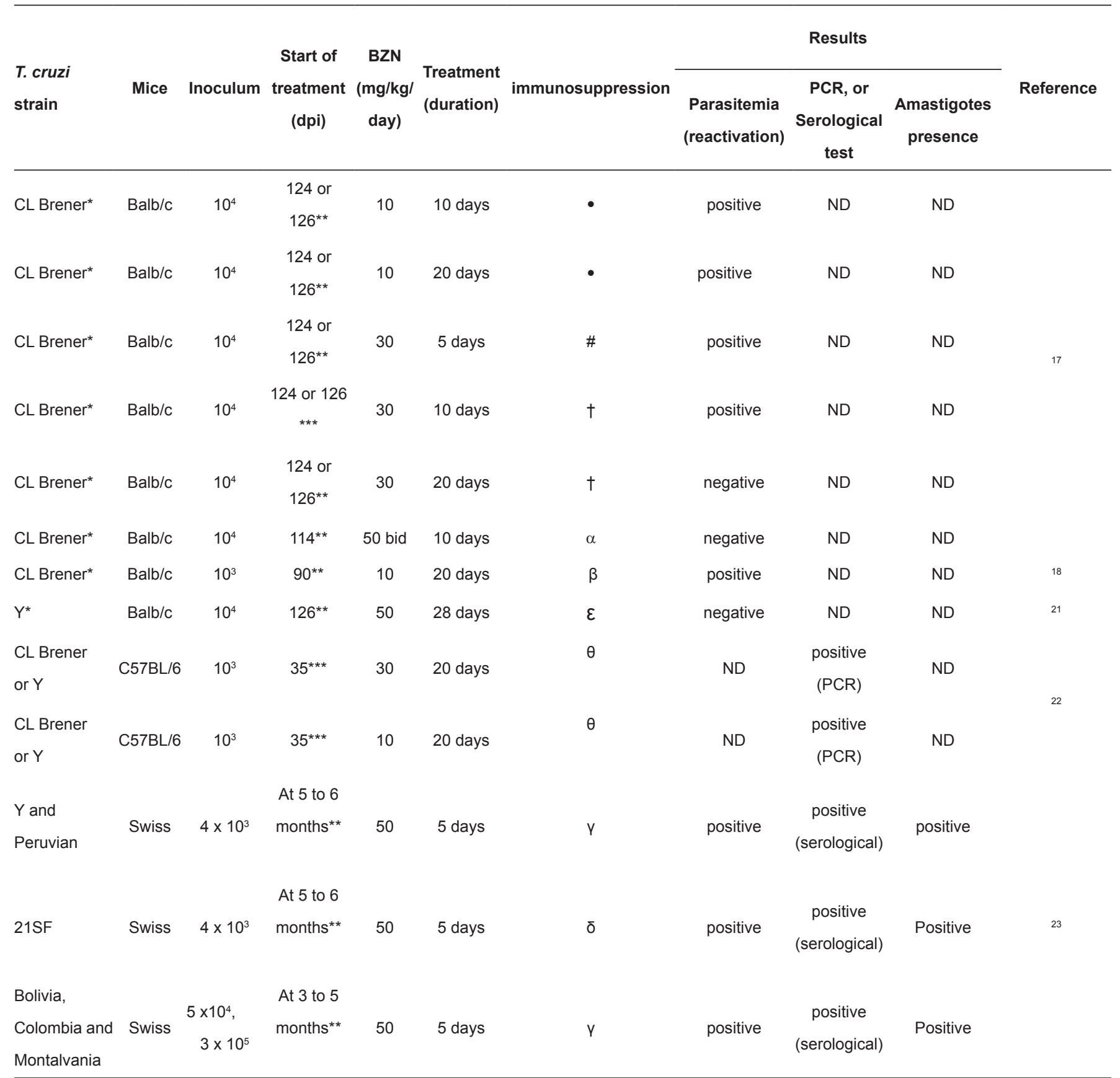

BZN: benznidazole; T. cruzi: Trypanosoma cruzi; dpi: days post-infection; PCR: polymerase chain reaction; ND: not determined; $\bullet$ : cyclophosphamide $(200 \mathrm{mg} \mathrm{kg}-1)$ by i.p. injection every 4 days for a maximum of 3 doses; \#: cyclophosphamide $(200 \mathrm{mg} / \mathrm{kg})$ on days 138 , 142 , and $146 \mathrm{dpi} ; \mathrm{t}$ : cyclophosphamide $(200 \mathrm{mg} / \mathrm{kg})$ on days 154,158 , and $162 \mathrm{dpi}$. $\boldsymbol{\alpha}$ : cyclophosphamide $(200 \mathrm{mg} / \mathrm{kg})$ on days 135,139 , and $143 \mathrm{dpi} ; \boldsymbol{\beta}$ : cyclophosphamide $(200 \mathrm{mg} / \mathrm{kg})$ on days 124 , 127,130 , and $133 \mathrm{dpi} ; \varepsilon$ : cyclophosphamide $(200 \mathrm{mg} \mathrm{kg}-1)$ by i.p. injection during 2 days at 3 -day intervals; $\boldsymbol{\theta}$ : cyclophosphamide $(200 \mathrm{mg} / \mathrm{kg})$ four cycles of cyclophosphamide with each cycle lasting one week; y: Azathioprine ( $2 \mathrm{mg} / \mathrm{kg} / \mathrm{day})$ gavage, betamethasone (1 $\mathrm{mg} / \mathrm{kg} / \mathrm{day})$, cyclosporine (16, 10,8 and 6 $\mathrm{mg} / \mathrm{kg} /$ day); $\delta$ : Azathioprine (10mg/kg/day) gavage, betamethasone ( $2 \mathrm{mg} / \mathrm{kg} /$ day), cyclosporine (30 mg/kg/day) gavage. *Bioluminescent bloodstream-form of $T$. cruzi. ${ }^{* *}$ Chronic phase. ${ }^{* *}$ Late acute phase.

In addition to combination therapy, other strategies to overcome the extended duration and toxicity of treatment have included identification of new therapeutic targets for Chagas disease, drug discovery, drug repositioning, and re-dosing regimens for current drugs. In this context, researchers have optimized Chagas therapy using BZN/itraconazole in different doses $(50,75$, and $100 \mathrm{mg} / \mathrm{kg}$ ), and evaluated the therapeutic effect in an animal model infected with the Y strain of T. cruzi. When compared to compound-only groups $(100 \mathrm{mg} / \mathrm{kg}$ ), the combination therapy (BZN/itraconazole) showed a decrease in the treatment duration required to reduce the trypomastigote forms in animals. The concomitant treatment 
TABLE 3: Experimental studies involving chronic phase Chagas disease in animal models without immunosuppression.

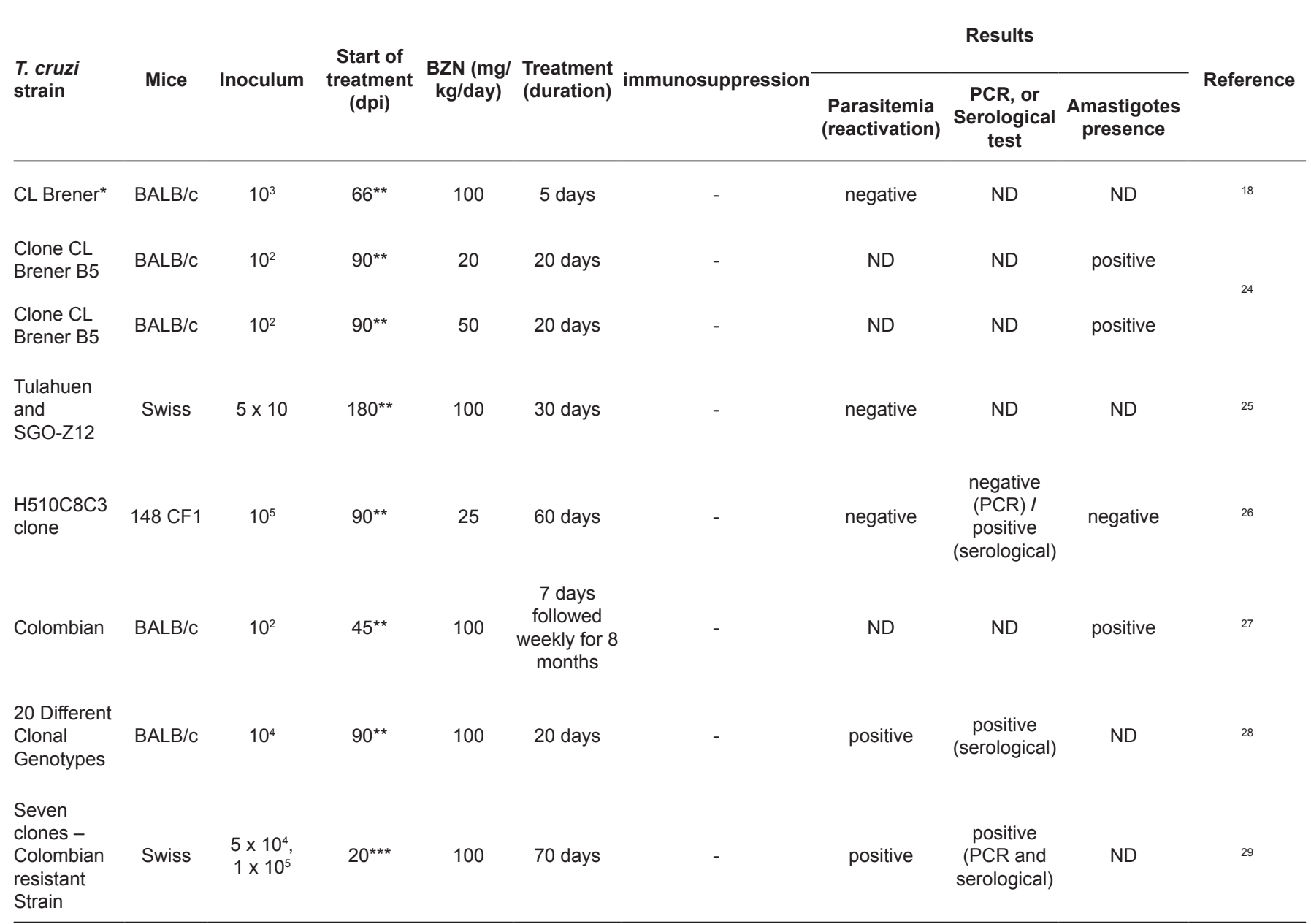

BZN: benznidazole; T. cruzi: Trypanosoma cruzi; dpi: days post-infection; PCR: polymerase chain reaction; ND: not determined; -: without immunosuppression. *Bioluminescent bloodstream-form of $T$. cruzi. ${ }^{* *}$ Chronic phase. ${ }^{* * *}$ Late acute phase.

also showed excellent immunomodulatory activity, mainly at the concentration of $75 \mathrm{mg} / \mathrm{kg}$, with a four-fold enhancement reported compared to the compound-only groups $(100 \mathrm{mg} / \mathrm{kg})^{34}$.

Researchers $^{35}$ have evaluated the concomitant treatment of BZN/pentoxifylline $(25 / 20 \mathrm{mg} / \mathrm{kg}$, respectively) during 30 consecutive days with mice chronically infected with the Colombian strain of T. cruzi. The combination therapy showed a reduction of approximately $79 \%$ of amastigote nests, which is 3\% more active than standard therapy with BZN (76\%). A decrease in myocarditis, fibrosis, TNF expression (37\%) in heart tissue, and improved electrical changes were also shown. These studies reinforce the importance of investigating previously-marketed drugs, particularly concomitant therapy with BZN against $T$. cruzi. This approach may provide a better quality of life for patients with Chagas disease and, for example, improve cardiac inflammatory levels, reduce biomarkers, and decrease treatment duration, as well as its concentration. As such, further studies concerning concomitant therapy for chronic Chagas disease are essential.

As well as smaller mammals such as rabbits and rats $^{36,37}$, larger animal models including dogs and non-human primates ${ }^{38-50}$ are also used for experimental studies, mainly in Chagas disease, due to these mammals' capacity to host parasites. Dogs and non-human primates (baboons, macaques, and capuchin monkeys) have been important experimental models to study the pathogenesis of Chagas disease, mainly in regard to the immunopathogenic mechanisms involved in the chronic phase of $T$. cruzi infection ${ }^{38,42-50}$. Electrocardiography alterations $\mathrm{s}^{39,40,47,49}$ have been reported in studies of dogs and nonhuman primates infected with several $T$. cruzi strains as well in studies using BZN chemotherapy in dogs who received the same regimen as humans $(7 \mathrm{mg} / \mathrm{kg})$, corroborating with the outcomes of other clinical trials ${ }^{42}$. Despite the variety of available experimental assays intended to simulate the $T$. cruzi infection, mice models have demonstrated more advantages than other experimental models, due to ease of handling, housing, greater sample numbers, and low cost, as well as the need to use a smaller drug quantity for the biological assays. In contrast, with larger animal models, the number of animals in a study is associated with ethical and cost considerations.

Considering that complete elimination is unlikely, the concentration of BZN should be decreased in the chronic phase of this disease in accordance with all the observed examples. 
Treatment can then be completed without interruption while enabling parasite reduction, and with less damage to tissue.

\section{LIMITED EFFECT IN HUMANS}

Human treatment with BZN is limited due to side effects, and BZN does not provide a cure for the chronic phase of Chagas disease. BZN administration using several different doses and treatment durations has shown no cure for patients in the chronic phase. In a clinical trial conducted with 195 patients using different BZN doses of between 50 and $500 \mathrm{mg}$ /day (equivalent of $5 \mathrm{mg} / \mathrm{kg} /$ day), approximately $30 \%$ of patients who received between 50 and $200 \mathrm{mg} /$ day discontinued treatment because of treatment side effects ${ }^{51}$.

Several studies conducted in chronically-infected patients using different concentrations of BZN showed adverse effects, and treatment discontinuity occurred ${ }^{52-55}$. One study involved 80 asymptomatic patients with Chagas disease who were treated with BZN $(5 \mathrm{mg} / \mathrm{kg} \text { twice daily for } 60 \text { days })^{56}$. The efficacy of BZN was evaluated over a period of three years, and only $5 \%$ of patients presented improvements. Another study ${ }^{57}$ monitored 13 patients chronically infected with Chagas disease. They were treated with BZN $5 \mathrm{mg} / \mathrm{kg}$ for 60 days. The accompaniment this patients lasted for more than four years and showed a decrease in the number of anti-T cruzi antibodies in $69 \%$ of patients ( 9 of 13 patients).

Researchers at the Chagas Disease Center in Buenos Aires ${ }^{58}$, Argentina, evaluated 566 patients (range, between 30 and 50 years of age), with 3 positive results on serologic tests (no cardiac failure). Half ( $\mathrm{n}=283$ ) of the patients received $5 \mathrm{mg} / \mathrm{kg}$ of BZN over 30 days, and the other half $(n=283)$ went without treatment. The study reported that BZN treatment increased negative seroconversion in the chagasic patients and decreased the disease progression, principally reducing cardiac alterations due to the parasite. This result confirmed the limitations of BZN therapy in the chronic phase of Chagas disease, but should not be used as an argument for inefficacy.

\section{THE TRANSITION TO CLINICAL TRIALS: A CHALLENGE FOR THE EXPERIMENTAL MODELS}

In recent years, results from clinical trials involving Chagas disease have been reported and new azole derivatives such as posaconazole, ravuconazole, and E1224 (ravuconazole prodrug) have been evaluated. Using crystallographic studies (PDB code: 3K1O), posaconazole demonstrated good enzyme inhibition and good affinity. The drug showed activity against T. cruzi during in vitro studies against the epimastigote and amastigote forms of the parasite, and also during in vivo studies in the chronic model of the disease. Furthermore, the compound showed activity against drug-resistant strains of $T$. cruzi, such as the $\mathrm{Y}$ and Colombian strains. Posaconazole has also been evaluated in clinical phase studies (ClinicalTrials. gov, NCT01377480) in Argentina, Bolivia, and Spain, and has been compared to BZN in adults with chronic Chagas disease. Preliminary results of these studies have shown that posaconazole was clearly inferior compared to standard therapy, possibly due to lower systemic bioavailability. After reporting this result, the pharmaceutical company, Merck, began a second attempt to investigate the co-administration of posaconazole and $\mathrm{BZN}^{59-65}$. However, researchers have recently reported that the drug candidate posaconazole was less active than BZN in highly sensitive models of bioluminescent $T$. cruzi ${ }^{66}$. In the same way, ravuconazole (8) and compound E-1224 (9) (a ravuconazole prodrug) have also shown potent in vitro activity against $T$. cruzi. Although ravuconazole has an unfavorable pharmacokinetic profile in animal models (characterized with a very short elimination half-life), its pharmacokinetic parameters in humans have led to clinical trials of E-1224 (ClinicalTrials. gov NCT01489228). The results of these trials demonstrated that this compound did not remain effective after one year of treatment when compared to BZN. In addition, the incidence and severity of adverse effects at high doses led to discontinuation of treatment in the phase II clinical trial ${ }^{67-70}$.

Despite efforts, and the number and quality of available experimental models intended to simulate Chagas disease, the results were disappointing in the clinical trials. Specifically, more confident predictions of the efficacy of these new drugs is required prior to starting clinical trials. Therefore, it is extremely important that better and safer methods are identified to improve the transition to clinical trials.

\section{SCIENTIFIC CHALLENGES}

More active compounds to treat the chronic phase of Chagas disease are urgently required and toxicity needs to be a strongly considered factor in the development of these compounds. The use of drug combinations that eliminate the intracellular parasites should not cause large quantities of tissue lesions. The best experimental protocol is one that effectively relates to human response.

The data shown here suggest that, for an experimental protocol in animals chronically infected with Chagas disease, treatment at lower doses $(<100 \mathrm{mg} / \mathrm{kg} /$ day $)$ of BZN is more advantageous and may be used as a basis to compare new drugs with BZN during the chronic phase of Chagas disease.

\section{Acknowledgment}

The authors would like to thank the Programa de Apoio ao Desenvolvimento Científico da Faculdade de Ciências Farmacêuticas da Universidade Estadual Paulista Júlio de Mesquita Filho (PADC/FCF-UNESP).

\section{Financial support}

We wish to thank the Coordenação de Aperfeiçoamento Pessoal de Nivel Superior (CAPES) for research fellowships and financial assistance.

\section{Conflict of interest}

The authors declare that there is no conflict of interest. 


\section{REFERENCES}

1. World Health Organization. Chagas disease in Latin America: an epidemiological update based on 2010 estimates. Wkly Epidemiol Rec. 2015;90(6):33-44.

2. Maya JD, Bollo S, Núnez-Vergara LJ, Squella JA, Repetto Y, Morello A, et al. Trypanosoma cruzi: effect and mode of action of nitroimidazole and nitrofuran derivatives. Biochem Pharmacol. 2003;65(6):999-1006.

3. Castro JA, de Mecca MM, Bartel LC. Toxic side effects of drugs used to treat Chagas disease (American trypanosomiasis). Hum Exp Toxicol. 2006;25(8):471-9.

4. Viotti R, Vigliano C, Lococo B, Alvarez MG, Petti M, Bertocchi $\mathrm{G}$, et al. Side effects of benznidazole as treatment in chronic Chagas disease: fears and realities. Expert Rev Anti Infect Ther. 2009;7(2):157-63.

5. de Andrade ALSS, Zicker F, de Oliveira RM, Silva SA, Luquetti A, Travassos LR, et al. Randomised trial of efficacy of benznidazole in treatment of early Trypanosoma cruzi infection. Lancet. 1996;348(9039):1407-13.

6. Sosa-Estani S, Segura EL, Ruiz AM, Velazquez E, Porcel BM, Yampotis C. Efficacy of chemotherapy with benznidazole in children in the indeterminate phase of Chagas disease. Am J Trop Med Hyg. 1998;59(4):526-9.

7. Colantonio LD, Prado N, Segura EL, Sosa-Estani S. Electrocardiographic abnormalities and treatment with benznidazole among children with chronic infection by Trypanosoma cruzi: a retrospective cohort study. PLoS Negl Trop Dis. 2016;10(5):1-15.

8. Coura JR, Borges-Pereira J. Chagas disease: What is known and what should be improved: a systemic review. Rev Soc Bras Med Trop. 2012;45(3):286-96.

9. Coura JR, De Castro SL. A critical review on chagas disease chemotherapy. Mem Inst Oswaldo Cruz. 2002;97(1):3-24.

10. Urbina JA, Docampo R. Specific chemotherapy of Chagas disease: Controversies and advances. Trends Parasitol. 2003;19(11):495-501.

11. Castro JA, de Mecca MM, Bartel LC. Toxic side effects of drugs used to treat Chagas disease (American trypanosomiasis). Hum Exp Toxicol. 2006;25(8):471-79.

12. Ferreira HO. Tratamento da forma indeterminada da doença de Chagas com nifurtimox e benznidazol. Rev Soc Bras Med Trop. 1990;23(4):209-21.

13. Suasnábar F, Arias E, Streiger M. Evolutive behaviour towards cardiomyopathy of treated (nifurtimox or benznidazole) and untreated chronic chagasic patients. Rev Inst Med Trop São Paulo. 2000;42(2):99-109.

14. Viotti R, Vigliano C, Armenti H, Segura E. Treatment of chronic Chagas disease with benznidazole: clinical and serological evolution of patients with long-term follow-up. Am Hear J. 1994;127(1):151-62.

15. Lauria-Pires L, Braga MS, Vexenat AC, Nitz N, Simões-Barbosa A, Tinoco DL, et al. Progressive chronic Chagas heart disease ten years after treatment with anti-Trypanosoma cruzi nitroderivatives. Am J Trop Med Hyg. 2000;63(3-4):111-8.

16. Braga MS, Lauria-Pires L, Argañaraz ER, Nascimento RJ, Teixeira ARL. Persistent infections in chronic Chagas disease patients treated with anti-Trypanosoma cruzi nitroderivatives. Rev Inst Med Trop São Paulo. 2000;42(3):157-61.

17. Cançado J. Long term evaluation of etiological treatment of chagas disease with benznidazole. Rev Inst Med Trop São Paulo. 2002;44(1):29-37.
18. Francisco AF, Jayawardhana S, Lewis MD, White KL, Shackleford $\mathrm{DM}$, Chen $\mathrm{G}$, et al. Nitroheterocyclic drugs cure experimental Trypanosoma cruzi infections more effectively in the chronic stage than in the acute stage. Sci Rep. 2016;6 (35351):1-11.

19. Francisco AF, Lewis MD, Jayawardhana S, Taylor MC, Chatelain E, Kelly JM. Limited ability of posaconazole to cure both acute and chronic Trypanosoma cruzi Infections revealed by highly sensitive in vivo imaging. Antimicrob Agents Chemother. 2015;59(8):4653-61.

20. Lewis MD, Francisco AF, Taylor MC, Kelly JM. A new experimental model for assessing drug efficacy against Trypanosoma cruzi infection based on highly sensitive in vivo imaging. J Biomol Screen. 2015;20(1):36-43.

21. Calvet CM, Choi Y, Thomas D, Suzuki B, Hirata K, LostraccoJohnson S, et al. 4-aminopyridyl-based lead compounds targeting CYP51 prevent spontaneous parasite relapse in a chronic model and improve cardiac pathology in an acute model of Trypanosoma cruzi infection. PLoS Neg1 Trop Dis. 2017;11(12):e0006132.

22. Khare S, Liu X, Stinson M, Rivera I, Groessl T, Tuntland T, et al. Antitrypanosomal treatment with benznidazole is superior to posaconazole regimens in mouse models of Chagas disease. Antimicrob Agents Chemother. 2015;59(10):6385-94.

23. Andrade S, Carneiro FA, de Souza A, de Lima E, Andrade Z. Influence of treatment with immunosuppressive drugs in mice chronically infected with Trypanosoma cruzi. Int J Exp Pathol.1997;78(6):391-99.

24. Esperandim VR, Ferreira DS, Toldo MPA, Saraiva J, Augusto MB, De Albuquerque S. New method for quantification of Trypanosoma cruzi in animal's tissue in the chronic phase of experimental Chagas disease. Parasitol Res. 2010;106(6):1471-73.

25. Bustamante JM, Presti MSL, Rivarola HW, Fernández AR, Enders JE, Fretes RE, et al. Treatment with benznidazole or thioridazine in the chronic phase of experimental Chagas disease improves cardiopathy. Int J Antimicrob Agents 2007;29(6):733-37.

26. Zaidenberg A, Luong T, Lirussi D, Bleiz J, Del Buono MB, Quijano $\mathrm{G}$, et al. Treatment of experimental chronic chagas disease with trifluralin. Basic Clin Pharmacol Toxicol. 2006;98(4):351-56.

27. Garcia S, Ramos CO, Senra JFV, Vilas-Boas F, Rodrigues MM, Campos-de-Carvalho AC, et al. Treatment with benznidazole during the chronic phase of experimental Chagas disease decreases cardiac alterations. Antimicrob Agents Chemother. 2005;49(4):1521-28.

28. Toledo MJDO, Bahia MT, Carneiro CM, Martins-Filho AO, Tibayrenc M, Barnabé C, et al. Chemotherapy with benznidazole and itraconazole for mice infected with different Trypanosoma cruzi clonal genotypes. Antimicrob Agents Chemother. 2003;47(1):22330.

29. Camandaroba ELP, Reis EAG, Gonçalves MS, Reis MG, Andrade SG. Trypanosoma cruzi: susceptibility to chemotherapy with benznidazole of clones isolated from the highly resistant Colombian strain. Rev Soc Bras Med Trop. 2003;36(2):201-9.

30. Pinazo MJ, Espinosa G, Cortes-Lletget C, Posada EJ, Aldasoro E, Oliveira I, et al. Immunosuppression and Chagas disease: a management challenge. PLoS Negl Trop Dis. 2013;7(1):1-9.

31. Taniwaki NN, Gonçalves VM, Romero JK, Silva CV, Silva S, Mortara RA. Trypanosoma cruzi strains in the Calomys callosus: parasitemia and reaction of intracellular forms with stage-specific antibodies in the acute and chronic phase of infection and after immunosuppression. Parasitol Res. 2011;109(2):431-40.

32. Penitente AR, Leite ALJ, Costa GP, Shrestha D, Horta AL, Natali AJ, et al. Enalapril in combination with benznidazole reduces cardiac inflammation and creatine kinases in mice chronically infected with Trypanosoma cruzi. Am J. Trop. Med. Hyg. 2015;93(5):976-82. 
33. Leite ALJ, Costa GP, Lopes LR, Mota LWR, Vieira PMA, Talvani A. The immunomodulatory effects of the Enalapril in combination with benznidazole during acute and chronic phases of the experimental infection with Trypanosoma cruzi. Acta Trop. 2017; 174(5):136-45.

34. Martins TAF, Diniz LF, Mazzeti AL, da Silva do Nascimento AF, Caldas S, Caldas IS, et al. Benznidazole/itraconazole combination treatment enhances anti-Trypanosoma cruzi activity in experimental Chagas disease. PLoS One. 2015;10(6):1-12.

35. Vilar-Pereira G, Pereira IR, Ruivo AS, Moreira OC, Silva AA, Britto C, et al. Combination chemotherapy with suboptimal doses of benznidazole and pentoxifylline sustains partial reversion of experimental Chagas' heart disease. Antimicrob Agents Chemother. 2016;60(7):4297-309.

36. Perez AR, Fontanella GH, Nocito AL, Revelli S, Bottasso OA. Short treatment with the tumour necrosis factor-alpha blocker infliximab diminishes chronic chagasic myocarditis in rats without evidence of Trypanosoma cruzi reactivation. Clin Exp Immunol. 2009;157(2):291-9.

37. Ramirez LE, Brener Z. Evaluation of the rabbit as a model for Chagas' disease. I. Parasitological studies. Mem Inst Oswaldo Cruz. 1987;82(4):531-6.

38. Guedes PM, Veloso VM, Afonso LC, Caliari MV, Carneiro CM, Diniz LF, et al. Development of chronic cardiomyopathy in canine Chagas disease correlates with high IFN-gamma, TNF-alpha, and low IL-10 production during the acute infection phase. Vet Immunol Immunopathol. 2009;130(1-2):43-52.

39. Cruz-Chan JV, Bolio-Gonzalez M, Colin-Flores R, Ramirez-Sierra MJ, Quijano-Hernandez I, Dumonteil E. Immunopathology of natural infection with Trypanosoma cruzi in dogs. Vet Parasitol. 2009;162(1-2):151-5.

40. Barbabosa-Pliego A, Diaz-Albiter HM, Ochoa-García L, AparicioBurgos E, López-Heydeck SM, Velásquez-Ordoñez V, et al. Trypanosoma cruzi circulating in the Southern region of the State of Mexico (Zumpahuacan) are pathogenic: a dog model. Am J Trop Med Hyg. 2009;81(3):390-5.

41. Guedes PM, Veloso VM, Tafuri WL, Galvão LM, Carneiro CM, Lana MD, et al. The dog as model for chemotherapy of the Chagas' disease. Acta Trop. 2002;84(1):9-17.

42. Bonecini-Almeida Mda G, Galvao-Castro B, Pessoa MH, Pirmez C, Laranja F. Experimental Chagas' disease in Rhesus monkeys. I. Clinical, parasitological, hematological and anatomo-pathological studies in the acute and indeterminate phase of the disease. Mem Inst Oswaldo Cruz. 1990;85(2):163-71.

43. Falasca CA, Grana DR, Mareso EA, Gomez E, Gili MM. Electrocardiographic changes in chronic Trypanosoma cruzi infected Cebus apella monkeys. Arq Bras Cardiol. 1991;56(4):287-93.

44. Samudio M, Montenegro-James S, Kasamatsu E, Cabral M, Schinini A, Rojas De Arias A, et al. Local and systemic cytokine expression during experimental chronic Trypanosoma cruzi infection in a Cebus monkey model. Parasite Immunol. 1999;21(9):451-60.

45. Rosner IM, Bellasai J, Schinini A, Rovira T, de Arias AR, Ferro EA, et al. Cardiomyopathy in Cebus apella monkeys experimentally infected with Trypanosoma cruzi. Trop Med Parasitol. 1989;40(1):24-31.

46. Malchiodi EL, Carbonetto CH, Grana D, Eiguchi de Palmero K, Chiaramonte $\mathrm{MG}$, Falasca CA, et al. Immune response against Trypanosoma cruzi antigens in Cebus apella monkeys. Trop Med Parasitol. 1993;44(2):86-90.

47. Almeida EA, Navarro MR, Guariento ME, Carvalhal SS. Infecção experimental de macacos Cebus apella sp pelo Trypanosoma cruzi. Avaliação clínica, eletrocardiqgráfica e anatomopatológica. Rev Soc Bras Med Trop. 1992;25(1):7-12.
48. de Meirelles MN, Bonecini-Almeida MG, Pessoa MH, GalvãoCastro B. Trypanosoma cruzi: experimental Chagas' disease in Rhesus monkeys. II. Ultrastructural and cytochemical studies of peroxidase and acid phosphatase activities. Mem Inst Oswaldo Cruz. 1990;85(2):173-81.

49. Milei J, Bolomo NJ, Vazquez A, Nagle CA. Normal and pathological electrocardiographic patterns in the Cebus monkey. J Med Primatol. 1982;11(1):10-9.

50. Bolomo N, Milei J, Cossio PM, Segura E, Laguens RP, Fernández LM, et al. Experimental Chagas' disease in a South American primate (Cebus sp). Medicina (B Aires). 1980;40(6 Pt 1):667-72.

51. Sperandio da Silva GM, Mediano MFF, Alvarenga Americano do Brasil PE, da Costa Chambela M, da Silva JA, de Sousa AS, et al. A clinical adverse drug reaction prediction model for patients with chagas disease treated with benznidazole. Antimicrob Agents Chemother. 2014;58(11):6371-7.

52. Morillo CA, Marin-Neto JA, Avezum A, Sosa-Estani S, Rassi Jr A, Rosas F, et al. Randomized trial of benznidazole for chronic Chagas cardiomyopathy. N Engl J Med. 2015;373(14):1295-6.

53. Soy D, Aldasoro E, Guerrero L, Posada E, Serret N, Mejía T, et al. Population pharmacokinetics of benznidazole in adult patients with Chagas disease. Antimicrob Agents Chemother. 2015;59(6):3342-49.

54. Fernandez ML, Riarte AR, Marson ME, Mastrantonio G, Ramirez JC, Schijman AG, et al. Pharmacokinetic and pharmacodynamic responses in adult patients with Chagas disease treated with a new formulation of benznidazole. Mem Inst Oswaldo Cruz. 2016;111(3):218-21.

55. Hasslocher-Moreno AM, do Brasil PEAA, de Sousa AS, Xavier SS, Chambela MC, da Silva GMS. Safety of benznidazole use in the treatment of chronic Chagas disease. J Antimicrob Chemother. 2012;67(5):1261-66.

56. Fernandes CD, Tiecher FM, Balbinot MM, Liarte DB, Scholl $\mathrm{D}$, Steindel $\mathrm{M}$, et al. Efficacy of benznidazol treatment for asymptomatic chagasic patients from state of Rio Grande do Sul evaluated during a three years follow-up. Mem Inst Oswaldo Cruz. 2009;104(1):27-32.

57. Andrade MC, Oliveira MF, Nagao-Dias AT, Coêlho ICB, Cândido DS, Freitas EC, et al. Clinical and serological evolution in chronic Chagas disease patients in a 4-year pharmacotherapy follow-up: a preliminary study. Rev Soc Bras Med Trop. 2013;46(6):776-78.

58. Viotti R, Vigliano C, Lococo B, Bertocchi G, Petti M, Alvarez $\mathrm{MG}$, et al. Long-term cardiac outcomes of treating chronic Chagas disease with benznidazole versus no treatment. Ann Intern Med. 2006;144(5):724-34.

59. Li Y, Theuretzbacher U, Clancy CJ, Ngunyen MH, Derendorf H. Pharmacokinetic/pharmacodynamic profile of posaconazole. Clin Pharmacokinet. 2010;49(6):379-96.

60. Pinazo MJ, Espinosa G, Gallego M, Lopez-Chejade PL, Urbina JA, Gascon J. Successful treatment with posaconazole of a patient with chronic Chagas disease and systemic lupus erythematosus. Am J Trop Med Hyg. 2010;82(4):583-7.

61. Lepesheva GI, Hargrove TY, Anderson S, Kleshchenko Y, Furtak V, Wawrzak Z, et al. Structural insights into inhibition of sterol 14alpha-demethylase in the human pathogen Trypanosoma cruzi. J Biol Chem. 2010;285(33):25582-90.

62. Urbina JA, Payares G, Contreras LM, Sanoja C, Molina J, Piras $\mathrm{M}$, et al. Antiproliferative effects and mechanism of action of SCH 56592 against Trypanosoma (Schizotrypanum) cruzi: In Vitro and In Vivo studies. Antimicrob Agents Chemother. 1998;42(7): 1771-7. 
63. Molina J, Martins-Filho O, Brener Z, Romanha AJ, Loebenberg D, Urbina JA. Activities of the triazole derivative SCH 56592 (Posaconazole) against drug-resistant strains of the protozoan parasite Trypanosoma (Schizotrypanum) cruzi in immunocompetent and immunosuppressed murine hosts. Antimicrob Agents Chemother. 2000;44(1):150-5.

64. Diniz LF, Urbina JA, de Andrade IM, Mazzeti AL, Martins TAF, Caldas IS, et al. Benznidazole and posaconazole in experimental Chagas disease: positive interaction in concomitant and sequential treatments. PLoS Negl Trop Dis. 2013;7(8):e2367.

65. United States National Library of Medicine. A study of the use of oral posaconazole (POS) in the treatment of asymptomatic chronic Chagas disease (P05267) (STOP CHAGAS). Clinical Trials.gov; 2012. Available at: http://clinicaltrials.gov/show/NCT0 1377480.

66. Francisco AF, Lewis MD, Jayawardhana S, Taylor MC, Chatelain E, Kelly JM. Limited ability of posaconazole to cure both acute and chronic Trypanosoma cruzi infections revealed by highly sensitive in vivo imaging. Antimicrob Agents Chemother. 2015;59(8): 4653-61.

67. Urbina JA, Payares G, Sanoja S, Lira R, Romanha AJ. In vitro and in vivo activities of ravuconazole on Trypanosoma cruzi, the causative agent of Chagas disease. Int J Antimicrob Agents. 2003;21(1):27-38.

68. Yamaguchi H. Potential of ravuconazole and its prodrugs as the new oral therapeutics for onychomycosis. Med Mycol J. 2016;57(4):E93-E110.

69. United States National Library of Medicine. Pivotal study of fexinidazole for human African Trypanosomiasis in Stage 2. Clinical Trials.gov; 2012. Available at: https://clinicaltrials.gov/ct2/ show/NCT01685827.

70. Diniz LDF, Caldas IS, Guedes PMDM, Crepalde G, de Lana GM, Carneiro CM, et al. Effects of ravuconazole treatment on parasite load and immune response in dogs experimentally infected with Trypanosoma cruzi. Antimicrob Agents Chemother. 2010;54(7)2979-86. 